\title{
Sistem Pemberian Dana Kartu Jakarta Pintar (KJP) Dengan Menggunakan Metode Topsis
}

\author{
Yuli Komalasari \\ Program Studi Teknologi Informasi Universitas Bina Sarana Informatika \\ e-mail: yuli.yks@bsi.ac.id
}

Cara Sitasi: Komalasari, Y. (2019). SISTEM PEMBERIAN DANA KARTU JAKARTA PINTAR (KJP) DENGAN MENGGUNAKAN METODE TOPSIS. Paradigma - Jurnal Komputer dan Informatika, 21(2), 221226. doi:10.31294/p.v21i2.5467

\begin{abstract}
The Jakarta Smart Card Program (KJP) has been carried out by various educational institutions at the elementary school level for almost seven years. There are 3 (three) criteria for determining whether or not students deserve the KJP assistance fund. Each criterion consists of several stages of sub criteria. The first criterion is to look at Household Member Information consisting of 6 (six) sub criteria, then the second criteria is to look at socio-economic conditions. This socio-economic condition consists of 5 (five) sub-criteria, and the third condition is to look at the condition of household assets consisting of 8 (eight) sub-criteria. The methodology / research approach used in evaluating the KJP program is to use the Technique for Order of Preference by Similarity to Ideal Solution (TOPSIS) method. The research was conducted to evaluate KJP funds whether it was on target, namely at the YAMPI Madrasah Ibtidaiyah (MI) school. Samples were taken from 5th grade students. The results of calculations using the Topsis method for the first, second and third grade students of MI YAMPI Al - Muttaqien were Elvara Salsabila, Kevin Erlin Fadhillah and Murti Diah Rahayu.
\end{abstract}

Keywords : Jakarta Pintar Card, Topsis Method

\section{PENDAHULUAN}

Guna mencerdaskan bangsa dan pemerataan pendidikan bagi penduduk Provinsi DKI Jakarta yang tidak mampu, pada akhir tahun 2012, tepatnya pada tanggal 01 Desember 2012 Pemerintah Provinsi DKI Jakarta memberikan dana bantuan biaya pendidikan kepada siswa-siswi yang tidak mampu. Dana bantuan biaya pendidikan tersebut dinamakan Kartu Jakarta Pintar.

Kartu Jakarta Pintar atau yang disingkat dengan istilah KJP adalah kartu yang disediakan Pemerintah DKI Jakarta bekerja sama dengan Bank DKI untuk diberikan kepada peserta didik dari keluarga tidak mampu sebagai sarana pengambilan bantuan (Afriansyah, 2017).

Menurut data Dinas Pendidikan total jumlah penerima KJP tahap pertama di tahun 2016 mencapai 531.007 siswa. Dengan rincian, siswa sekolah negeri mencapai 310.118 siswa atau 58,3 persen dan sekolah swasta sebesar 220.889 atau 41,7 persen.

Manfaat yang paling utama dari pemberian dana bantuan KJP tersebut adalah Seluruh warga DKI Jakarta menamatkan pendidikan minimal sampai dengan jenjang SMA/SMK, mutu pendidikan di Provinsi DKI Jakarta meningkat secara signifikan dan Peningkatan pencapaian target Angka
Partisipasi Kasar (APK) pendidikan dasar dan Menengah.

Dana bantuan Kartu Jakarta Pintar (KJP) juga diberikan kepada siswa-siswi MI YAMPI. Pemberian dana bantuan tersebut diberikan kepada siswa-siswi yang tidak mampu.

Untuk mendapatkan dana bantuan KJP tersebut, siswa -siswi yang mengajukan bantuan dengan mengisi formulir yang telah disediakan dan melampirkan beberapa persyaratan, kemudian data tersebut dicek kembali oleh pihak sekolah. Dari data yang ada diketahui apakah siswa-siswi tersebut yang mengajukan KJP berhak mendapatkan dana bantuan KJP atau tidak.

Banyaknya KJP yang telah diterbitkan hingga tahun 2016 dan besarnya dana yang telah dicairkan oleh Pemerintah Provinsi DKI Jakarta membutuhkan metode yang handal untuk mengawasi pemberian KJP dan pencairan dana tersebut. Potensi pemberian dana KJP yang tidak tepat sasaran mempunyai probabilitas yang tinggi. Manfaat dari pemberian dana KJP harus diawasi melalui sekolah-sekolah yang berkaitan langsung menerima dana bantuan KJP tersebut.

Sistem pemberikan dana bantuan KJP disekolah MI YAMPI masih manual, pengecekan instrument atau data-data yang ada dicek satu persatu sampai pengajuan disetujui. 
Berdasarkan hal tersebut diatas penulis mengusulkan dengan Metode TOPSIS. Metode TOPSIS ini membantu dalam membuat keputusan apakah siswa-siswi layak untuk mendapatkan dana bantuan KJP

Prinsip dasarnya adalah bahwa alternatif yang dipilih harus memiliki jarak terpendek dari solusi ideal positif dan jarak terjauh dari solusi ideal negatif. Dalam TOPSIS, rating kinerja dan bobot kriteria tersebut diberikan sebagai nilai crisp.

Keuntungan utama dari TOPSIS dibanding dengan Metode MADM lainnya dalam pengambilan keputusan masalah yang kompleks adalah mudah digunakan, dapat memperhitungkan semua jenis kriteria (subyektif dan obyektif), logika rasional dan mudah dipahami bagi para praktisi, perhitungan proses sangat mudah, konsep memungkinkan mengejar kriteria alternatif terbaik digambarkan dalam matematika secara sederhana, dan bobot penting dapat dimasukkan dengan mudah. (Nasab, H.H., Milani, A.S., 2012).

Pengidentifikasian masalah KJP ini digunakan metode Technique for Order of Preference by Similarity to Ideal Solution (TOPSIS) untuk perangkingan siswa yang mendapatkan dana bantuan KJP.

Berdasarkan latar belakang penulisan, maka rumusan masalah penelitian yaitu:

a. Bagaimanakah membuat langkah-langkah perhitungan dari persyaratan yang akan mendapatkan dana bantuan KJP?

b. Bagaimanakan langkah-langkah tersebut dibuat dengan menggunakan Metode Topsis ?

c. Bagaimanakah hasil dari perangkingan siswa yang mendapatkan dana bantuan KJP tersebut?

Berdasarkan identifikasi masalah diatas, diharapkan menghasilkan informasi dana bantuan KJP tersebut apakah sudah tepat sasaran dalam penyalurannya kepada siswa-siswi yang menerimanya dan adapun tujuan penelitian tersebut adalah

a. Memperoleh langkah-langkah perhitungan persyaratan dana bantuan Kartu Jakarta Pintar (KJP) ditingkat Sekolah Dasar.

b. Menghasilkan cara perhitungan dengan menggunakan Metode Topsis.

c. Mendapatkan tingkat siswa yang mendapatkan dana bantuan Kartu Jakarta Pintar (KJP) .

\section{METODOLOGI PENELITIAN}

1. Metodolagi Penelitian yang dilakukan dapat dijelaskan dalam flowchart metode penelitian (Sumadi Suryabrata, B.A, M.A, Ed.S, Ph.D, 2012) sebagai berikut :

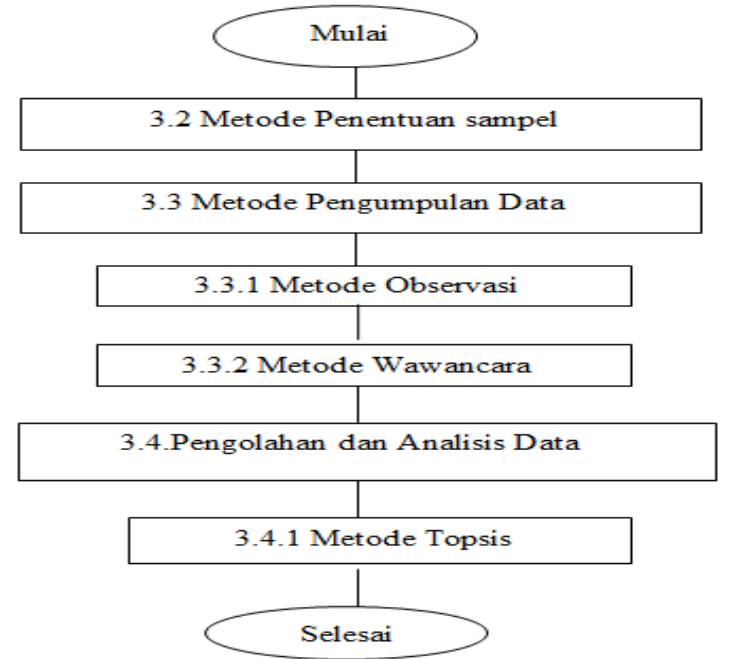

Gambar 1 Flowchart Penelitian

2. Metode penentuan sampel

Sampel untuk pengumpulan data yang akan digunakan dalam penelitian ini dilakukan pada sampel tingkat Sekolah Dasar terdiri dari :

Sekolah Islam MI YAMPI siswa kelas 5 sebanyak 16 (enam belas) siswa.

3. Metode pengumpulan data

Beberapa hal yang dilkukan untuk mendapatkan suatu informasi tentang penerima dana bantuan Kartu Jakarta Pintar (KJP) yang dibutuhkan yaitu wawancara dan observasi.

Hasil dari wawancara dan observasi yang dilakukan pada Sekolah Dasar didapatkan data-data primer untuk mendukung proses penulisan yaitu :

1. Tabel Data Siswa Penerima KJP

2. Tabel Data Survei calon penerima KJP. Tabel ini berisi tabel kriteria pengambilan keputusan oleh Verifikator, yaitu memenuhi/tidak memenuhi syarat sebagai calon penerima KJP.

\section{Pengolahan Dan Analisis Data}

1. Metode Topsis

Metode yang diusulkan adalah metode TOPSIS (Technique for Order of Preference by Similarity to Ideal Solution). adalah model pendukung keputusan multikriteria yang diperkenalkan oleh Yoon Dan Hwang.

Prinsip dasarnya adalah bahwa alternatif yang dipilih harus memiliki jarak terpendek dari solusi ideal positif dan jarak terjauh dari solusi ideal negatif (Ashtiani, B., Haghighirad, F., Makui, A., Montazer,G.A., 2008).

Metodologi Penelitian dengan TOPSIS

a. Membuat kriteria dan alternatif untuk perangkingan KJP. Masing-masing kriteria diberi nilai bobot.

b. Pembentukan matriks berpasangan yang terdiri dari $m$ alternatif dan $n$ kriteria yaitu untuk menentukan grade dari masing-masing alternatif terhadap kriteria

c. Menghitung normalisasi matriks

d. Menghitung solusi positif dan negatif 
e. Menghitung separation measure

f. Menghitung kedekatan relatif dan dibuat Perangkingan

g. Menghitung perkalian matriks dari hasil prioritas model kriteria dan alternatif untuk mendapatkan keputusan akhir.

Pada metode topsis ini dilakukan perhitungan untuk perangkingan calon penerimaan peserta KJP dengan mengambil data yang diberikan oleh calon penerima bantuan KJP.

2. Perangkingan calon penerimaan KJP.

a. Membuat matriks keputusan yang ternormalisasi.

b. Menentukan matriks solusi ideal positif dan matriks solusi ideal negatif.

c. Menentukan jarak antara nilai setiap alternatif dengan matriks solusi ideal positif dan matriks ideal negatif.

d. Menentukan nilai preferensi untuk setiap alternatif yaitu didapat dari $\mathrm{RC}^{*}$.

\section{HASIL DAN PEMBAHASAN}

\section{Hasil Penelitian}

Berdasarkan hasil perhitungan menggunakan dengan metode TOPSIS akan diperoleh rangking siswa yang mendapatkan dana bantuan KJP (Kartu Jakarta Pintar).

a. Hasil perhitungan tabel instrument KJP Terdapat tiga buah tabel (tabel informasi anggota rumah tangga yaitu tabel kondisi social ekonomi dan tabel kondisi asset rumah tangga) yang harus dilengkapi oleh peserta KJP (Kartu Jakarta Pintar). Pemberian nilai masing-masing subkriteria adalah dari total $100 \%$ dibagi beberapa subkriteria.

Tabel 1 Informasi Anggota Rumah Tangga

\begin{tabular}{|l|l|l|l|l|}
\hline $\begin{array}{l}\text { Bagaimana kondisi } \\
\text { demografis rumah } \\
\text { tangga? }\end{array}$ & Status & Nilai & skor & Total \\
\hline $\begin{array}{l}\text { 1. Kepala rumah } \\
\text { tangga memiliki } \\
\text { pendidikan SMA } \\
\text { kebawah/Tidak }\end{array}$ & Tidak & 0 & 16,6 & 0 \\
\hline $\begin{array}{l}\text { 2. Kepala rumah } \\
\text { tangga } \\
\text { mempunyai } \\
\text { pekerjaan tidak } \\
\text { tetap/PHK / } \\
\text { Tidak }\end{array}$ & & & & \\
\hline $\begin{array}{l}\text { 3. Kepala rumah } \\
\text { tangga memiliki } \\
\text { penyakit kronis } \\
\text { /yang Tidak } \\
\text { menyulitkan } \\
\text { untuk bekerja / } \\
\text { Tidak }\end{array}$ & & 0 & 16,6 & 0 \\
\hline $\begin{array}{l}\text { 4. Salah satu atau } \\
\text { kedua orang tua } \\
\text { kandung sudah } \\
\text { meninggal } \\
\text { dunia/Tidak }\end{array}$ & & & & \\
\hline $\begin{array}{l}\text { 5. Ada anak dalam } \\
\text { keluarga antara }\end{array}$ & Tidak & 0 & 16,6 & 0 \\
\hline
\end{tabular}

\begin{tabular}{|c|c|c|c|c|}
\hline $\begin{array}{l}\text { umur } 7-18 \text { tahun } \\
\text { yang sedang } \\
\text { tidak bersekolah } \\
\text { karena alasan } \\
\text { ekonomi/Tidak }\end{array}$ & & & & \\
\hline $\begin{array}{l}\text { 6. Ayah/Ibu } \\
\text { pegawai/ } \\
\text { karyawan } \\
\text { swasta/wiraswast } \\
\text { awan } \\
\text { berpenghasilan } \\
\text { cukup /Tidak. }\end{array}$ & Tidak & 1 & 16,6 & 16,67 \\
\hline TOTAL & & & & 16,67 \\
\hline
\end{tabular}

Tabel 2 Kondisi Sosial Ekonomi

\begin{tabular}{|l|c|c|c|c|}
\hline $\begin{array}{l}\text { Bagaimana kondisi } \\
\text { sosial-ekonomi } \\
\text { rumah tangga ? }\end{array}$ & Status & Nilai & skor & Total \\
\hline $\begin{array}{l}\text { 1. Tempat tinggal yg } \\
\text { ditempati bukan } \\
\text { milik sendiri? }\end{array}$ & Ya & 1 & 20 & 20 \\
\hline $\begin{array}{l}\text { 2. Luas lantai } \\
\text { bangunan tempat } \\
\text { tinggal kurang } \\
\text { dari 8m2 } \\
\text { per orang? }\end{array}$ & Ya & 1 & 20 & 20 \\
\hline $\begin{array}{l}\text { 3.Sumber } \\
\text { penerangan rumah } \\
\text { tangga tidak } \\
\text { menggunakan } \\
\text { listrik atau } \\
\text { menggunakan } \\
\text { listrik dengan } \\
\text { daya dibawah atau } \\
\text { sama dengan } 450 \\
\text { watt? }\end{array}$ & Ya & 1 & 20 & 20 \\
\hline $\begin{array}{l}\text { 4.Sumber air minum } \\
\text { berasal dari sumur } \\
?\end{array}$ & Ya & 1 & 20 & 20 \\
\hline $\begin{array}{l}\text { 5.Bahan bakar untuk } \\
\text { memasak sehari- } \\
\text { hari adlh kayu } \\
\text { Bakar / gas } \\
\text { 3kg/tidak } \\
\text { memasak? }\end{array}$ & Ya & 1 & 20 & 20 \\
\hline TOTAL & & & & \\
\hline
\end{tabular}

Tabel 3 Kondisi Aset Rumah Tangga

\begin{tabular}{|l|c|c|c|c|}
\hline $\begin{array}{l}\text { Apakah rumah } \\
\text { tangga memiliki } \\
\text { asset sbb : ? }\end{array}$ & Status & Nila & skor & Total \\
\hline 1. Mobil & Tidak & 1 & 12,5 & 12,5 \\
\hline 2. Kapal Motor & Tidak & 1 & 12,5 & 12,5 \\
\hline $\begin{array}{l}\text { 3. PerahuMotor } \\
\text { lebih dari 1 }\end{array}$ & Tidak & 1 & 12,5 & 12,5 \\
\hline $\begin{array}{l}\text { 4. Sepeda Motor } \\
\text { lebih dari 1 }\end{array}$ & Tidak & 1 & 12,5 & 12,5 \\
\hline 5. Telepon Rumah & Tidak & 1 & 12,5 & 12,5 \\
\hline $\begin{array}{l}\text { 6. Anak memiliki HP } \\
\text { seharga diatas Rp } \\
\text { 1.000.000 }\end{array}$ & Tidak & 1 & 12,5 & 12,5 \\
\hline \multicolumn{1}{|c|}{ TOTAL } & & & & $\mathbf{1 0 0}$ \\
\hline
\end{tabular}

Setelah ketiga kriteria dilengkapi oleh calon penerima KJP, maka dilakukan pengujian dengan metode TOPSIS, untuk melihat siswa mana yang mempunyai nilai tertinggi sehingga berhak mendapatkan dana bantuan KJP terlebih dahulu.

2. Perhitungan dengan Metode TOPSIS

a. Memberi Nilai Kepentingan 
1) Nilai1 Sangat Rendah

2) Nilai 2 Rendah

3) Nilai 3 Cukup

4) Nilai 4 Tinggi

5) Nilai 5 Sangat Tinggi

b. Memberi nilai kepentingan dari masing-masing nilai informasi survei

1) Kriteria A diberi nilai 5

2) Kriteria B diberi nilai 4

3) Kriteria $\mathrm{C}$ diberi nilai 2

c. Membuat "Hasil Perhitungan Survei" yaitu hasil perhitungan dimasukkan pada Tabel 4.

Tabel 4 Hasil perhitungan survey

\begin{tabular}{|c|c|c|c|c|}
\hline $\mathrm{NO}$ & NAMA SISWA & $\mathrm{A}$ & B & $\mathrm{C}$ \\
\hline 1 & Achmad Choirul & 50,0 & 80,0 & 100,0 \\
\hline 2 & Afriza Riski Prestyo & 33,3 & 80,0 & 100,0 \\
\hline 3 & Ardi Subektio & 50,0 & 100,0 & 100,0 \\
\hline 4 & Elvara Salsabilla & 33,3 & 40,0 & 100,0 \\
\hline 5 & Kevin Erlin Fadhillah & 50,0 & 40,0 & 100,0 \\
\hline 6 & $\begin{array}{l}\text { Muchamad Syaiful } \\
\text { Azriel }\end{array}$ & 80,0 & 80,0 & 100,0 \\
\hline 7 & Murti Diah Rahayu & 50,0 & 40,0 & 100,0 \\
\hline 8 & Nabila Arini & 33,3 & 80,0 & 100,0 \\
\hline 9 & $\begin{array}{l}\text { Norkia } \\
\text { Novianti }\end{array}$ Putri $\quad$ Ayu & 50,0 & 80,0 & 100,0 \\
\hline 10 & Novitasari & 50,0 & 100,0 & 100,0 \\
\hline 11 & Ria Eka Prasetia & 33,3 & 40,0 & 100,0 \\
\hline 12 & Rinata Putri & 50,0 & 80,0 & 100,0 \\
\hline 13 & $\begin{array}{ll}\text { Rizky } & \text { Taufik } \\
\text { Firmansyah } & \end{array}$ & 50,0 & 80,0 & 100,0 \\
\hline 14 & Safira Regina Aisy & 33,3 & 80,0 & 100,0 \\
\hline 15 & Siti Fatimah & 50,0 & 100,0 & 100,0 \\
\hline 16 & Tegar Prasetyo & 50,0 & 80,0 & 100,0 \\
\hline
\end{tabular}

d. Selanjutnya memberi kriteria pada perhitungan data survei pada Tabel 5 dapat dilihat pada

Tabel 5 dengan kriteria

1) Nilai 1 lebih kecil dari 60

2) Nilai 2 dari 61 dan lebih kecil dari 70

3) Nilai 3 dari 71 dan lebih kecil dari 80

4) Nilai 4 dari 81 dan lebih kecil dari 90

5) Nilai 5 diatas 90

Tabel 5 Kriteria Perhitungan

\begin{tabular}{|c|c|c|c|c|}
\hline $\mathrm{NO}$ & NAMA SISWA & $\mathrm{A}$ & B & $\mathrm{C}$ \\
\hline 1 & Achmad Choirul & 1 & 3 & 5 \\
\hline 2 & Afriza Riski Prestyo & 1 & 3 & 5 \\
\hline 3 & Ardi Subektio & 1 & 5 & 5 \\
\hline 4 & Elvara Salsabilla & 1 & 1 & 5 \\
\hline 5 & Kevin Erlin Fadhillah & 1 & 1 & 5 \\
\hline 6 & $\begin{array}{ll}\text { Muchamad } & \text { Syaiful } \\
\text { Azriel } & \\
\end{array}$ & 3 & 3 & 5 \\
\hline 7 & Murti Diah Rahayu & 1 & 1 & 5 \\
\hline 8 & Nabila Arini & 1 & 3 & 5 \\
\hline 9 & $\begin{array}{lll}\text { Norkia } & \text { Putri } & \text { Ayu } \\
\text { Novianti } & & \\
\end{array}$ & 1 & 3 & 5 \\
\hline 10 & Novitasari & 1 & 5 & 5 \\
\hline 11 & Ria Eka Prasetia & 1 & 1 & 5 \\
\hline 12 & Rinata Putri & 1 & 3 & 5 \\
\hline 13 & Rizky Taufik Firmansyah & 1 & 3 & 5 \\
\hline 14 & Safira Regina Aisy & 1 & 3 & 5 \\
\hline 15 & Siti Fatimah & 1 & 5 & 5 \\
\hline 16 & Tegar Prasetyo & 1 & 3 & 5 \\
\hline
\end{tabular}

e. Nilai pada kolom A, B dan $\mathrm{C}$ diakar kuadratkan, lihat pada Tabel 6

Tabel 6 Hasil Pengkuadratan Tabel 5

\begin{tabular}{|c|l|r|r|r|}
\hline NO & \multicolumn{1}{|c|}{ NAMA SISWA } & \multicolumn{1}{c|}{ A } & \multicolumn{1}{c|}{ B } & \multicolumn{1}{c|}{ C } \\
\hline 1 & Achmad Choirul & 1 & 9 & 25 \\
\hline 2 & Afriza Riski Prestyo & 1 & 9 & 25 \\
\hline 3 & Ardi Subektio & 1 & 25 & 25 \\
\hline 4 & Elvara Salsabilla & 1 & 1 & 25 \\
\hline 5 & Kevin Erlin Fadhillah & 1 & 1 & 25 \\
\hline & Muchamad Syaiful & & & \\
6 & Azriel & 9 & 9 & 25 \\
\hline 7 & Murti Diah Rahayu & 1 & 1 & 25 \\
\hline 8 & Nabila Arini & 1 & 9 & 25 \\
\hline & Norkia Putri Ayu & & & \\
\hline 9 & Novianti & 1 & 9 & 25 \\
\hline 10 & Novitasari & 1 & 25 & 25 \\
\hline 11 & Ria Eka Prasetia & 1 & 9 & 25 \\
\hline 12 & Rinata Putri & & & \\
\hline & Rizky Taufik & 1 & 9 & 25 \\
\hline 13 & Firmansyah & 1 & 9 & 25 \\
\hline 14 & Safira Regina Aisy & 1 & 9 & 25 \\
\hline 15 & Siti Fatimah & & 160 & 400 \\
\hline 16 & Tegar Prasetyo & & \\
\hline & TOTAL & & & 25 \\
\hline
\end{tabular}

\begin{tabular}{|l|l|l|l|}
\hline Pembagi & 4.8990 & 12.6491 & 20.0000 \\
\hline
\end{tabular}

f. Membuat "Tabel Keputusan Ternormalisasi" yaitu "Nilai Data Survei" dibagi dengan "Pembagi" masing-masing tiap-tiap kolom. Hasil perhitungan dapat dilihat pada Tabel 7

Tabel 7 Tabel Keputusan Ternormalisasi

\begin{tabular}{|c|c|c|c|c|}
\hline $\mathrm{NO}$ & NAMA SISWA & $\mathrm{A}$ & B & $\mathrm{C}$ \\
\hline 1 & Achmad Choirul & 0.2041 & 0.2372 & 0.2500 \\
\hline 2 & $\begin{array}{ll}\text { Afriza } & \text { Riski } \\
\text { Prestyo } & \\
\end{array}$ & 0.2041 & 0.2372 & 0.2500 \\
\hline 3 & Ardi Subektio & 0.2041 & 0.3953 & 0.2500 \\
\hline 4 & Elvara Salsabilla & 0.2041 & 0.0791 & 0.2500 \\
\hline 5 & $\begin{array}{ll}\text { Kevin } & \text { Erlin } \\
\text { Fadhillah } & \end{array}$ & 0.2041 & 0.0791 & 0.2500 \\
\hline 6 & $\begin{array}{l}\text { Muchamad Syaiful } \\
\text { Azriel }\end{array}$ & 0.6124 & 0.2372 & 0.2500 \\
\hline 7 & Murti Diah Rahayu & 0.2041 & 0.0791 & 0.2500 \\
\hline 8 & Nabila Arini & 0.2041 & 0.2372 & 0.2500 \\
\hline 9 & $\begin{array}{l}\text { Norkia Putri Ayu } \\
\text { Novianti }\end{array}$ & 0.2041 & 0.2372 & 0.2500 \\
\hline 10 & Novitasari & 0.2041 & 0.3953 & 0.2500 \\
\hline 11 & Ria Eka Prasetia & 0.2041 & 0.0791 & 0.2500 \\
\hline 12 & Rinata Putri & 0.2041 & 0.2372 & 0.2500 \\
\hline 13 & $\begin{array}{ll}\text { Rizky } & \text { Taufik } \\
\text { Firmansyah } & \\
\end{array}$ & 0.2041 & 0.2372 & 0.2500 \\
\hline 14 & Safira Regina Aisy & 0.2041 & 0.2372 & 0.2500 \\
\hline 15 & Siti Fatimah & 0.2041 & 0.3953 & 0.2500 \\
\hline 16 & Tegar Prasetyo & 0.2041 & 0.2372 & 0.2500 \\
\hline
\end{tabular}


g. Langkah selanjutnya adalah menghitung "Tabel Keputusan Ternormalisasi Terbobot" yaitu Solusi ideal dinotasikan A+, sedangkan solusi ideal negatif dinotasikan A-.Persamaan setiap nilai didalam tabel ternormalisasidibagi dengan bobot kriteria. Hasil perhitungan dapat dilihat pada Tabel 8 .

\begin{tabular}{|l|l|l|l|}
\hline Bobot & 5 & 4 & 2 \\
\hline
\end{tabular}

Tabel 8 Tabel Normalisasi Terbobot

\begin{tabular}{|c|l|c|c|c|}
\hline NO & \multicolumn{1}{|c|}{ NAMA SISWA } & A & B & C \\
\hline 1 & Achmad Choirul & 0.0408 & 0.0593 & 0.1250 \\
\hline 2 & $\begin{array}{l}\text { Afriza Riski } \\
\text { Prestyo }\end{array}$ & 0.0408 & 0.0593 & 0.1250 \\
\hline 3 & Ardi Subektio & 0.0408 & 0.0988 & 0.1250 \\
\hline 4 & Elvara Salsabilla & 0.0408 & 0.0198 & 0.1250 \\
\hline 5 & $\begin{array}{l}\text { Kevin Erlin } \\
\text { Fadhillah }\end{array}$ & 0.0408 & 0.0198 & 0.1250 \\
\hline 6 & $\begin{array}{l}\text { Muchamad Syaiful } \\
\text { Azriel }\end{array}$ & 0.1225 & 0.0593 & 0.1250 \\
\hline 7 & Murti Diah Rahayu & 0.0408 & 0.0198 & 0.1250 \\
\hline 8 & Nabila Arini & 0.0408 & 0.0593 & 0.1250 \\
\hline 9 & $\begin{array}{l}\text { Norkia Putri Ayu } \\
\text { Novianti }\end{array}$ & 0.0408 & 0.0593 & 0.1250 \\
\hline 10 & Novitasari & 0.0408 & 0.0988 & 0.1250 \\
\hline 11 & Ria Eka Prasetia & 0.0408 & 0.0198 & 0.1250 \\
\hline 12 & Rinata Putri & 0.0408 & 0.0593 & 0.1250 \\
\hline 13 & $\begin{array}{l}\text { Rizky Taufik } \\
\text { Firmansyah }\end{array}$ & 0.0408 & 0.0593 & 0.1250 \\
\hline 14 & Safira Regina Aisy & 0.0408 & 0.0593 & 0.1250 \\
\hline 15 & Siti Fatimah & 0.0408 & 0.0988 & 0.1250 \\
\hline 16 & Tegar Prasetyo & 0.0408 & 0.0593 & 0.1250 \\
\hline
\end{tabular}

Didapatkan matriks solusi ideal positif dan matriks solusi ideal negatif.

Tabel 9 Matrik solusi ideal positif dan negatif

\begin{tabular}{|l|l|l|l|}
\hline $\mathrm{A}^{*}$ & 0.1225 & 0.0988 & 0.1250 \\
\hline $\mathrm{A}-$ & 0.0408 & 0.0198 & 0.1250 \\
\hline
\end{tabular}

Nilai $A^{*}$ adalah nilai terbesar dari setiap kolom, sedang A- adalah nilai terkecil dari setiap kolom.
henghitung 'Separation Measure". Separation
measure ini pengukuran jarak dari suatu alternatif ke solusi ideal positif dan solusi ideal negatif. Hasil perhitungan "Separation Measure" dapat dilihat pada Tabel 10.

- $\mathrm{S}^{*}=$ Nilai Tabel Keputusan Ternomalisasi Terbobot pada $\mathrm{A}^{*}$ dikurangkan dengan nilai masing-masing pada setiap kolom dipangkatkan, ditambahkan pada nilai setiap kolom yang dikuadratkan lalu diakar kuadratkan.

- S- = Nilai Tabel Keputusan Ternomalisasi Terbobot pada A- dikurangkan dengan nilai masing-masing pada setiap kolom dipangkatkan, ditambahkan pada nilai setiap kolom yang dikuadratkan lalu diakar kuadratkan.

- $\mathrm{RC}^{*}=\mathrm{S} * /\left(\mathrm{S}^{*}+\mathrm{S}-\right)$

Menentukan jarak antara nilai setiap alternatif dengan matriks solusi ideal positif dan matriks ideal negatif) dan disebut juga (Tabel Jarak Alternatif/Hasil perangkingan yang mendapat dana KJP)

Tabel 10 Tabel Separation Measure

\begin{tabular}{|c|c|c|c|c|}
\hline $\mathrm{NO}$ & NAMA SISWA & $\mathrm{A}$ & $\mathrm{B}$ & $\mathrm{C}$ \\
\hline 1 & Achmad Choirul & 0.1212 & 0.0395 & 0.7540 \\
\hline 2 & $\begin{array}{ll}\text { Afriza } & \text { Riski } \\
\text { Prestyo } & \end{array}$ & 0.1212 & 0.0395 & 0.7540 \\
\hline 3 & Ardi Subektio & 0.0816 & $0.07 \varsigma$ & 0.5081 \\
\hline 4 & Elvara Salsabilla & 0.1607 & - & 1.000 \\
\hline 5 & $\begin{array}{ll}\text { Kevin } & \text { Erlin } \\
\text { Fadhillah } & \end{array}$ & 0.1607 & - & 1.0000 \\
\hline 6 & $\begin{array}{l}\text { Muchamad Syaiful } \\
\text { Azriel }\end{array}$ & 0.0395 & 0.1212 & 0.2460 \\
\hline 7 & Murti Diah Rahayu & 0.1607 & - & 1.000 \\
\hline 8 & Nabila Arini & 0.1212 & 0.0395 & 0.7540 \\
\hline 9 & $\begin{array}{l}\text { Norkia Putri Ayu } \\
\text { Novianti }\end{array}$ & 0.1212 & 0.0395 & 0.7540 \\
\hline 10 & Novitasari & 0.0816 & 0.0791 & 0.5081 \\
\hline 11 & Ria Eka Prasetia & 0.1607 & - & 1.0000 \\
\hline 12 & Rinata Putri & 0.1212 & 0.0395 & 0.7540 \\
\hline 13 & $\begin{array}{lr}\text { Rizky Taufik } \\
\text { Firmansyah }\end{array}$ & 0.1212 & 0.0395 & 0.7540 \\
\hline 14 & Safira Regina Aisy & 0.1212 & 0.0395 & 0.7540 \\
\hline 15 & Siti Fatimah & 0.0816 & 0.0791 & 0.5081 \\
\hline 16 & Tegar Prasetyo & 0.1212 & 0.0395 & 0.7540 \\
\hline
\end{tabular}

\section{KESIMPULAN}

Program Kartu Jakarta Pintar (KJP) telah dilaksanakan oleh berbagai lembaga pendidikan ditingkat sekolah dasar sejak tahun 2012, hingga saat ini sudah berjalan hampir 7 tahun. Belum ada metode ataupun sistem untuk membantu pemberian dana KJP. Diperlukan evaluasi keberhasilan KJP ini sebagai program nasional dalam meningkatkan mutu pendidikan dasar. Metodologi/pendekatan 
penelitian yang digunakan dalam mengevaluasi program KJP adalah menggunakan metode Technique for Order of Preference by Similarity to Ideal Solution (TOPSIS) dengan menggunakan langkah-langkah sebagai berikut :

1. Kriteria yang digunakan untuk mendapatkan Dana bantuan KJP adalah kriteria Informasi Anggota Rumah Tangga, Kondisi Sosial Ekonomi dan Aset Rumah Tangga.

2. Metode yang digunakan adalah menggunakan Metode Topsis.

3. Hasil perhitungan untuk mendapatkan dana bantuan KJP dengan menggunakan metode Topsis pada siswa kelas 5 di MI YAMPI Al Muttaqien adalah yang pertama, kedua dan ketiga adalah Ardi Subektio, Novitasari dan Siti Fatimah.

\section{REFERENSI}

Afriansyah, A. (2017). Implementasi Program Kartu Jakarta Pintar Di Dki: Peluang Dan Tantangan Dalam Pemenuhan Keadilan Sosial Di Bidang Pendidikan. Jurnal Kependudukan Indonesia, 12(1), 55. https://doi.org/10.14203/jki.v12i1.196

Ashtiani, B., Haghighirad, F., Makui, A., Montazer,G.A., 2008. Extension of Fuzzy TOPSIS Method Based on Interval-valued Fuzzy Sets Applied Soft Computing. Vol. 9, No.2, 457-461

Baskerville, R. L., (1999), Investigating Information System with Action Research, Communications of the Association for Information Systems (CAIS), vol 2 no 3.

Depdiknas. (2003). Undang-Undang Republik Indonesia Nomor 20 Tahun 2003, tentang Sistem Pendidikan Nasional.

Dinas Pendidikan Provinsi DKI Jakarta (2015) Petunjuk Teknik Bantan Biaya Personal Pendidikan Melalui Kartu Jakarta Pintar.

m.tempo,(2013),https://m.tempo.co/read/news/2015 /08/13/090691585/pemegang-kjp-tak-bisalagi-tarik-tunai-di-atm-bank-dki

Indrajit,(2008),(https://www.academia.edu/143501 69/Decision_Support_System), (diunduh 3 Januari 2017)

Nasab, H.H., Milani, A.S., 2012. An Improvement of Quantitative Strategic Planning Matrix Using Multiple Criteria Decision Making and Fuzzy Numbers. Applied Soft Computing 12, 2246-2253

Permendagri, (2011), Peraturan Menteri Dalam Negeri Nomonr 32 Tahun 2011, tentang Pedoman Pemberian Hibah dan Bantuan Sosial Yang Bersumber Dari Anggaran Dan Belanja Daerah.

Permendagri, (2012), Peraturan Menteri Dalam Negeri Nomonr 39 Tahun 2012, tentang
Perubahan atas Peraturan Menteri Dalam Negeri Nomor 32 Tahun 2011 tentang Pedoman Pemberian Hibah dan Bantuan

Pergub, (2015), Peraturan Gubernur Provinsi Daerah Khusus Ibukota Jakarta No.174, Tahun 2015, tentang Bantuan Biaya Personal Pendidikan Bagi Peserta Didik Dari Keluarga Tidak Mampu Melalui Kartu Jakarta Pintar.

Saaty, T. L., (1993), Pengambilan Keputusan Bagi Para Pimpinan : Proses Hirarki Analitik Untuk Pengambilan Keputusan Dalam Situasi Yang Komplek, PT. Pustaka Binaman Pressindo, Jakarta

Schluter,(1926),https://skripsimahasiswa.blogspot.c om/2008/l0/langkah-langkah-

penelitian.html14 Okt 2008 - Pelaksanaan penelitian dengan menggunakan metode ilmiah harus mengikuti ... Ada kalanya. perumusan masalah dan studi keputusan dapat dikerjakan secara bersamaan. ((diunduh 12/052017 pukul 20.00)

Siagan, M.P., (1991), Teori dan Praktek pengambilan Keputusan, CV. Haji Masagung, Jakarta.

Sumadi Suryabrata, B.A, M.A, Ed.S, Ph.D, (2012), Metodologi Penelitian, PT Raja Grafindo, Jakarta

Supranto Johanes, M.A., (1998), Teknik Pengambilan Keputusan, PT. Rineka Cipta, Jakarta.

Tulus (2004, pp.81-83) Peran disiplin pada perilaku dan prestasi siswa. Jakarta: Grasindo

Turban, Efraim \& Aronson, Jay E. (2001). Decision Support Systems and Intelligent Systems. 6th edition. Prentice Hall: Upper Saddle River, NJ.

\section{PROFIL PENULIS}

Yuli Komalasari, M.Kom Lahir di Jakarta, 15 Juli 1972, Tahun 1994 lulus Strata satu (S1) dari Universitas Gunadarma, Depok, Lulus Strasa dua (S2) Magister Ilmu Komputer STMIK Nusamandiri. Bergabung dengan Universitas Bina Sarana Informatika (UBSI) sejak tahun 2015. Sebelum bergabung dengan Universitas Bina Penulis bekerja di PT. Bank Danamon Indonesia mulai tahun 1994 sampai dengan tahun 2005 (Dibagian Kredit dan Product Development). Tahun 2005 sampai dengan tahun 2008 menjadi Konsultan ISO. Dan pada tahun 2008 hingga tahun 2015 bekerja di PT. Multi Square Indonesia (Dibagian Purchasing, Planner, dan terakhir di bagian HRD \& Keuangan) 